\title{
Strength Development and Water Permeability of Engineered Biomass Aggregate Pervious Concrete
}

\author{
S. Shahidan ${ }^{1, a}$, H. B. Koh ${ }^{1}$, A. M. Sharif Alansi ${ }^{1}$ and L. Y. Loon ${ }^{1}$ \\ ${ }^{1}$ Faculty of Civil and Environmental Engineering, Universiti Tun Hussein Onn Malaysia, 86400 Batu Pahat, Johor, \\ Malaysia
}

\begin{abstract}
Pervious concrete has a high rate of permeability, low strength and high porosity. It is commonly used in the area of storm water management. However, its use has been limited to pavements with low volume traffic. Pervious concrete is different from normal concrete as the mixture contains no fine aggregates. The aggregate is usually of a single size bonded by a cement paste. This study focuses mainly on the effect of Engineered Biomass Aggregate (EBA) on the compressive strength and permeability of previous concrete. Three types of mixtures with $0 \%$ natural aggregate (NA), $5 \%$ BA and $5 \%$ of EBA have been studied in this research. A total of $27150 \mathrm{~mm}$ cubes were casted in the laboratory for compressive strength and permeability test. This research aims to enhance the understanding of engineered biomass aggregate pervious concrete as well as the use of pervious concrete for sustainable construction activities due to the environmental benefits it offers.
\end{abstract}

\section{Introduction}

Concrete is considered as the major cause of natural material deployment. However there are many by-products such as waste material which become problematic to the environment. Biomass is conceded as by-product of industrial effluents and is continuously being dumped into landfills. However, research showed that biomass has the potential to be recycled and may be used to replace natural aggregates (NA) in concrete [1-3].

Comparing the properties of normal aggregate with biomass aggregate (BA), it is found that BA shows lower strength. The pervious concrete containing BA allows water to pass through it and is normally used in soft soil due to its lightweight properties [4]. Pervious concrete is also known as "nofines concrete" and consists of Portland cement, coarse aggregate, water, admixtures, and little or no sand [5-8]. It has high porosity used for concrete flatwork applications that allows water from precipitation and other sources to pass through it, thereby reducing the runoff from a site and recharging ground water levels.

Besides that, Polyethylene or plastic bags also affect the environment due to wide availability and the fact that they are not biodegradable. Plastic bags can be recycled and used to produce Engineered Biomass Aggregate (EBA) [7]. However, engineering technical data on EBA is not well established due to the lack of research on this material. Therefore, this research aims to study the strength

\footnotetext{
${ }^{a}$ Corresponding author : shahiron@uthm.edu.my
} 
development and water permeability of pervious concrete containing BA and EBA as alternative materials for sustainable development.

\section{Biomass Aggregate and Engineered Biomass Aggregate}

Biomass Aggregate (BA) is derived primarily from the innovative exploitation of solid wastes from controlled incineration of biomass. The BA used in this research was collected from a factory called Evergreen Fibreboard Sdn. Bhd. located in Parit Raja. The BA is the waste from the furnace which burns wood bark and palm oil fibre as shown in Figure 1. Previous research shows that BA is lightweight and complies with most of the lightweight aggregate properties. The density of BA ranges from $300 \mathrm{~kg} / \mathrm{m}^{3}$ to $800 \mathrm{~kg} / \mathrm{m}^{3}$ [8-9]. BA is suitable as construction material for road pavements, interlocking blocks for pathways, lightweight aggregate concrete and etc.

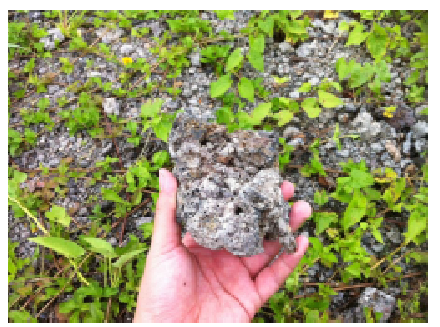

Figure 1. Biomas aggregate.

Engineered Biomass Aggregate (EBA) is a new material derived from combinations of 2 recyclable materials which are biomass aggregate and polyethylene or plastic bag. The BA was wrapped with polyethylene and placed together inside the oven with a temperature of $200^{\circ} \mathrm{C}$ for half an hour. Figure 2 presents the process of manufacturing EBA.
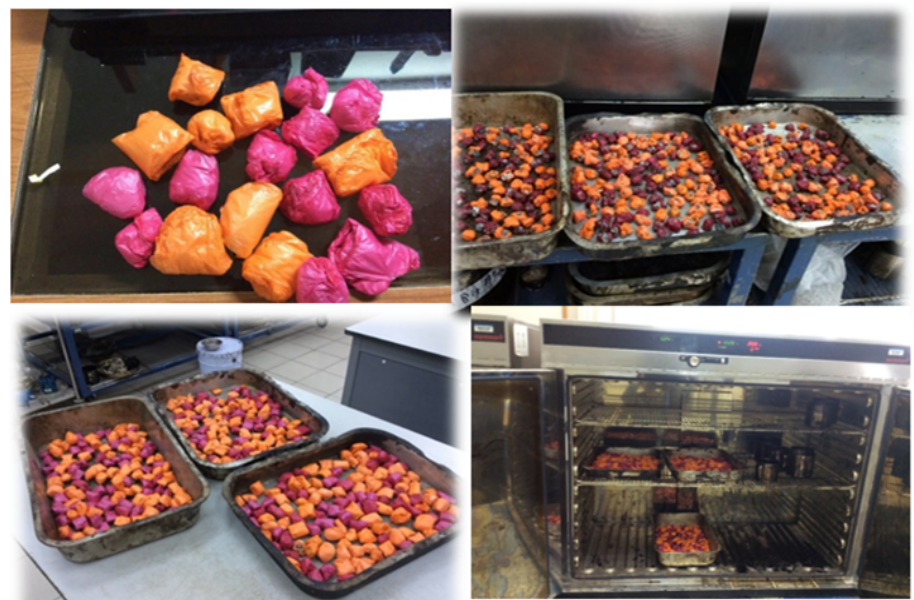

Figure 2. Engineered biomass aggregate (EBA).

\section{Laboratory Work}

At the initial stage, all the materials and equipment have to be prepared and checked for availability in order to determine the performance of concrete with BA and EBA. All the testing and laboratory work were carried out according to British Standards. 


\subsection{Materials and cube preparations}

The constituent materials used in this research were composite cement, course aggregate, water, BA, EBA and superplasticizers (SP). A total of 27 pervious concrete cubes with a size of $150 \mathrm{~mm} \times 150$ $\mathrm{mm} \times 150 \mathrm{~mm}$ each with $0 \% \mathrm{NA}(8-14 \mathrm{~mm}), 5 \%$ BA and 5\% EBA were prepared with water cement ratio 0.45 . Table 1 shows the mix design proportions used in this investigation.

Table 1. Mix design proportions.

\begin{tabular}{|c|c|c|c|c|c|c|}
\hline Type of Mix & $\begin{array}{c}\text { Water } \\
\left(\mathbf{k g} / \mathbf{m}^{\mathbf{3}}\right)\end{array}$ & $\begin{array}{c}\text { Cement } \\
\left(\mathbf{k g} / \mathbf{m}^{\mathbf{3}}\right)\end{array}$ & $\begin{array}{c}\text { Coarse Aggregate }\left(\mathbf{k g} / \mathbf{m}^{\mathbf{3}}\right) \\
(\mathbf{8 - 1 4}) \mathbf{m m}\end{array}$ & $\begin{array}{c}\mathbf{B A} \\
\left(\mathbf{k g} / \mathbf{m}^{\mathbf{3}}\right)\end{array}$ & $\begin{array}{c}\mathbf{E B A} \\
\left(\mathbf{k g} / \mathbf{m}^{\mathbf{3}}\right)\end{array}$ & $\mathbf{S P} \mathbf{1 \%}$ \\
\hline $100 \%$ NA & 114 & 380 & 1620 & - & - & 3.8 \\
\hline $95 \% \mathrm{NA}+5 \% \mathrm{BA}$ & 114 & 380 & 1539 & 81 & - & 3.8 \\
\hline $95 \% \mathrm{NA}+5 \% \mathrm{EBA}$ & 114 & 380 & 1539 & - & 81 & 3.8 \\
\hline
\end{tabular}

The materials were stored properly in the laboratory room so that the stability of surface moisture content of the aggregate is maintained. This is because pervious concrete has low and high water content aggregate content. All the materials were mixed together in the mixture machine with the proportion design as shown in Table 1. After completing the mixture process, the pervious concrete was poured into the cube mould and left for a day. On the following day, the pervious concrete was placed into the curing tank for the curing process to take place.

\subsection{Testing}

Two types of tests were conducted. A compressive strength test, as shown in Figure 3(a), was carried out to determine the short-term strength development (7, 14 and 28 days) of pervious concrete containing BA and EBA. Meanwhile, permeability test was conducted on the $150 \mathrm{~mm}$ pervious concrete cubes at 28 days. Permeability is an important parameter of previous concrete since the material is designed to function as a drainage layer in pavement structures. Darcy's law for laminar flow is no longer applicable for previous concrete. In this study, a permeability measurement device and method developed for drainable asphalt mixture similar to pervious concrete in function were used as seen in Figure 3(b).

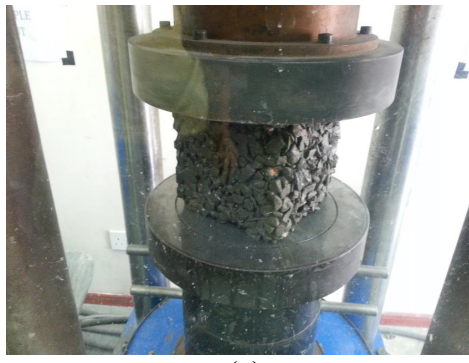

(a)

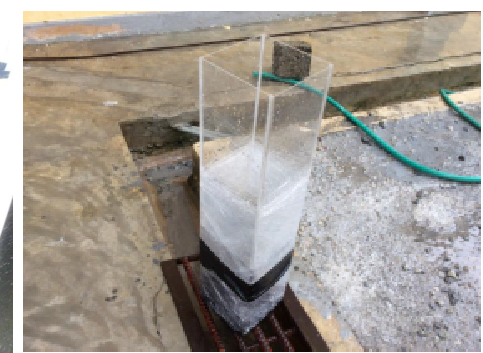

(b)

Figure 3. Testing method: (a) Compressive strength test, and (b) Permeability test.

\section{Results and Discussion}

\subsection{Compressive strength}

Figure 4 shows the result of compressive strength for 7, 14 and 28 days of curing age. The results show that control specimen of $0 \%$ NA gained higher value compared to other specimens. NA achieved $15.69 \mathrm{MPa}$ at 28 days but 5\% BA and 5\% EBA only achieved $13.4 \mathrm{MPa}$ and $10.5 \mathrm{MPa}$, 
respectively. Pervious concrete containing 5\% EBA achieved the lowest compressive strength. This may be due to the smooth surface of EBA which reduces interlocking between the aggregates. Besides, the mechanical strength of biomass aggregates is generally lower than that of natural aggregates. Overall, the trend of strength development for pervious concrete and pervious concrete containing BA and EBA is similar to normal concrete.

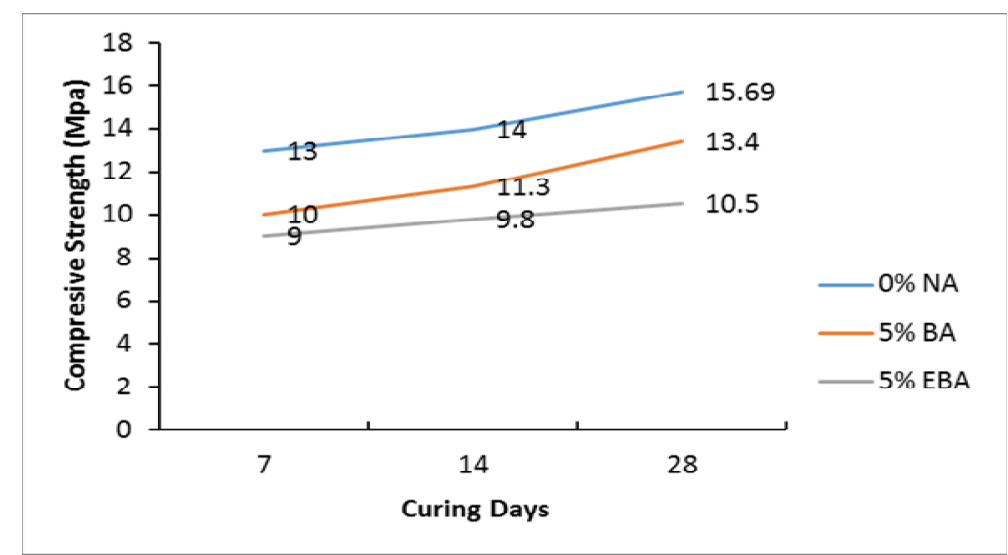

Figure 4. Compressive strength of pervious concrete.

\subsection{Water permeability test}

The concept of flow rate in this experiment is to determine the duration of water passing through the cubes. The result was obtained by using tubes with specific diminution to calculate the discharge and determine the time of water passing through the specimen. The test was conducted on the cube specimens after 28 days of water curing. Fig 5 shows that the specimen containing $5 \%$ of EBA achieved higher water permeability followed by $5 \%$ BA and NA. The water permeability of $5 \%$ EBA, $5 \% \mathrm{BA}$ and NA are $14.33 \mathrm{~mm} / \mathrm{s}, 12.15 \mathrm{~mm} / \mathrm{s}$ and $6.83 \mathrm{~mm} / \mathrm{s}$, respectively. Therefore, pervious concrete containing EBA has the highest flow rate compared to normal pervious concrete. The increase in water permeability for pervious concrete containing 5\% EBA is due to the wrapping of BA with polyethylene which makes the surface of EBA smooth.

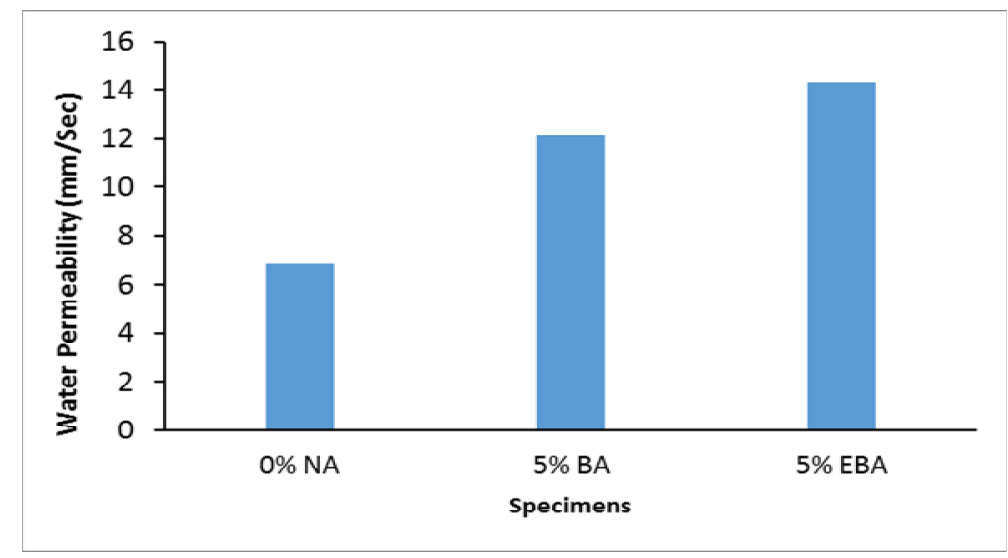

Figure 5. Water permeability test. 


\subsection{Relationship between water permeability and compressive strength}

In general, the compressive strength increases when the water permeability decreases. The relationship between water permeability and 28-day compressive strength for pervious concrete is shown in Figure 6.

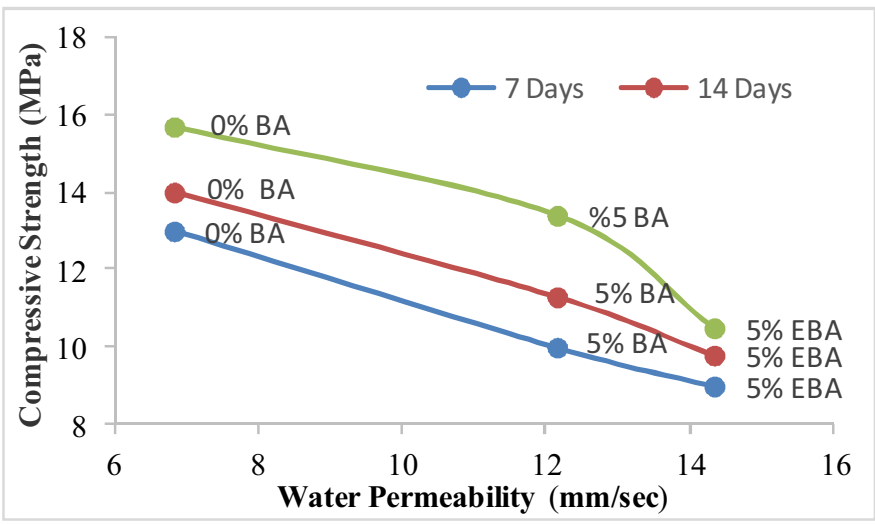

Figure 6. The relationship between water permeability and compressive strength

Figure 6 illustrated that the NA specimen achieved approximately $6.83 \mathrm{~mm} / \mathrm{sec}$ for water pemeability with a compressive strength of $15.69 \mathrm{MPa}$. However the strength of concrete decreased slightly by adding $5 \%$ of BA and $5 \%$ of EBA. From the graph it can be concluded that, the water permeability may be increased by adding $5 \%$ of EBA compared to $0 \%$ of NA and $5 \%$ of BA but the compressive strength is decreased after the addition of BA and EBA.

\section{Conclusions}

From the above findings, it can be concluded that Biomass Aggregate (BA) and Engineered Biomass Aggregate (EBA) are suitable to be used as the partial replacement for natural aggregate in pervious concrete to increase water permeability. Further research should be carried out to improve the strength of BA and EBA concrete in order to maximize the use of sustainable materials for civil engineering applications.

\section{References}

[1] Y.L. Lee, A.K. Ahmad Tarmizi, A.R. Ismail, H.B. Koh, S. Hani, S. Nagapan, R. Fetra Venny and C.T. Jung, Alternative aggregates for sustainable construction, International J. of Zero Waste Generation, 1(1), 5-10, (2013).

[2] Y.L. Lee, K.O. Khoo, S.S.F. Chong and M.W. Hussin, Strength development and water permeability of high strength TIA concrete, Proceedings of International Congress on Creating with Concrete, University of Dundee, 175-181, (1999).

[3] Y.L. Lee, K.S. Goh, K.O. Khoo and I. Bakar, Foamed aggregate pervious concrete - an option for road on peat, Proceedings of MUCET, (2009).

[4] Y.L. Lee, T.J. Chai, R. Fetra Venny, H.B. Koh, Y. David and A.K. Ahmad Tarmizi, Biomass aggregate for sustainable geopolymer concrete, International Journal of Civil Engineering and Technology, 5(3), 340-356, (2014).

[5] F. Montes and L. Haselbach. measuring hydraulic conductivity in pervious concrete, Environmental Engineering Science Journal. November 23(6), 960-969, (2006). 


\section{MATEC Web of Conferences}

[6] ASTM C39, Standard Test Method for Compressive Strength of Cylindrical Concrete Specimens, ASTM International, (2009).

[7] BS EN 12390-3, Testing Hardened Concrete, Compressive Strength of Test Specimens, BSI Standards Publication, (2009).

[8] S. Demie, M.F. Nuruddin, M.F. Ahmeed and N. Shafiq, Effects of curing temperature and superplasticizer on workability and compressive strength of self-compacting geopolymer concrete, IEEE, 5(11), 187-194, (2011).

[9] L.M. Haselbach, S. Valavala and F. Montes, Permeability predictions for sand-clogged Portland cement pervious concrete pavement systems, Journal of Environmental Management, 81, 42-49, (2006). 